\title{
Crecimiento y metabolismo de Fischerella TB22 en medio de cultivo BG11 ${ }^{0}$
}

\section{(Growth and metabolism of Fischerella TB22 in BG110 culture medium)}

\author{
Martínez-Rosales, A. ${ }^{1}$, Trujillo-Tapia, M. N. ${ }^{1 *}$, Ramírez-Fuentes, E. ${ }^{1}$ \\ ${ }^{1}$ Universidad del Mar, Campus Puerto Ángel. Carretera Puerto Ángel-Zipolite Km. 1.5. Cd. \\ Universitaria S/N. C.P. 70902. San Pedro Pochutla, Oaxaca, México. Tel: (+52 958) 5843057 \\ *Autor para correspondencia: nieves@angel.umar.mx
}

RECIBIDO: 11 de agosto 2020

APROBADO: 1 de septiembre 2020

DOI: $10.22370 /$ bolmicol.2020.35.1.2425

Palabras claves: Cianobacteria, amonio, fotobioreactores, crecimiento microbiano, sonicación, densidad óptica.

Keywords: Cyanobacteria, ammonia, photobioreactors, microbial growth, sonication, optical density.

\section{RESUMEN}

Los microorganismos fijadores de nitrógeno de vida libre, abarcan una gama morfológica que va desde los organismos unicelulares como las bacterias y algunas cianobacterias, hasta multicelulares, filamentosas, por ello es importante conocer cómo se comportan y se puede saber haciendo una curva de crecimiento microbiano. Para este estudio se prepararon 4 fotobioreactores de columna burbujeada con inoculo de Fischerella TB22, se pusieron en aireación constante con 12 horas luz y 12 horas obscuridad durante 40 días con diferentes tratamientos de ajuste de volumen del medio de cultivo y ajuste del $\mathrm{pH}$. El objetivo de este trabajo fue evaluar el crecimiento en biomasa por peso seco, densidad óptica, $\mathrm{pH}$ y amonio de Fischerella $s p$. en medio de cultivo $\mathrm{BG} 11^{0}$ durante 12 días. Las variables que se midieron de la curva de crecimiento de las cianobacterias, siguieron el patrón de una curva típica de crecimiento microbiano.

\begin{abstract}
Free-living nitrogen-fixing microorganisms cover a morphological range that goes from unicellular organisms such as bacteria and some cyanobacteria, to multicellular, filamentous, therefore it is important to know how they behave and can be known by making a microbial growth curve. For this study, 4 bubbled column photobioreactors with Fischerella TB22 inoculum were prepared, they were placed in constant aeration with 12 hours of light and 12 hours of darkness for 40 days with different treatments of volume adjustment of the culture medium and $\mathrm{pH}$ adjustment. The objective of this work was to evaluate the biomass growth by dry weight, optical density, $\mathrm{pH}$, and ammonia of Fischerella sp. in the BG $11^{0}$ culture medium for 12 days. The variables that were measured from the growth curve of cyanobacteria followed the pattern of a typical microbial growth curve.
\end{abstract}


Crecimiento y metabolismo de Fischerella TB22 en medio de cultivo BG1 $1^{0}$. - Martínez-Rosales, A.

\section{INTRODUCCIÓN}

En los últimos años las microalgas se han convertido en una fuente prometedora y sustentable para la producción de compuestos de interés comercial, ya que al ser microorganismos autótrofos solo requieren de agua, luz (como fuente de energía) y $\mathrm{CO}_{2}$ (como fuente de carbono) $)^{1}$. Las cianobacterias son microorganismos procariotas conocidos como algas verde-azules o cianofitas ${ }^{2}$. Por muchos años las cianobacterias fueron consideradas algas verdes azuladas debido a su fototrofía oxigénica. La estructura fina de las cianobacterias es bien conocida $^{3}$. Son organismos fotoautótrofos, que realizan la fotosíntesis con liberación de oxígeno, presentan clorofila a como pigmento fotosintético primario y ficobiliproteínas como pigmentos auxiliares ${ }^{4}$. Algunos microorganismos en especial las cianobacterias se reproducen por división celular, por lo cual presentan un crecimiento rápido cuando se inoculan en un medio de cultivo no limitante y se mantienen en condiciones adecuadas. Las condiciones ambientales cambian con la edad del cultivo, por lo cual, se modifica también la velocidad de crecimiento poblacional $^{5}$. El crecimiento de un cultivo se expresa como el incremento de biomasa ya sea en forma de número de células (cél $/ \mathrm{mL}$ ), en peso seco (total y/u orgánico), cantidad de proteína, de pigmentos, medidos directamente $\mathrm{o}$ en unidades arbitrarias de fluorescencia, volumen de las células o carbono celular total, calculado para un período de tiempo o una fase de crecimiento específica ${ }^{6}$. Esto permite reconocer diferentes fases de crecimiento (figura 1), las cuales sirven para describir la forma en la cual cambia la concentración celular o biomasa.

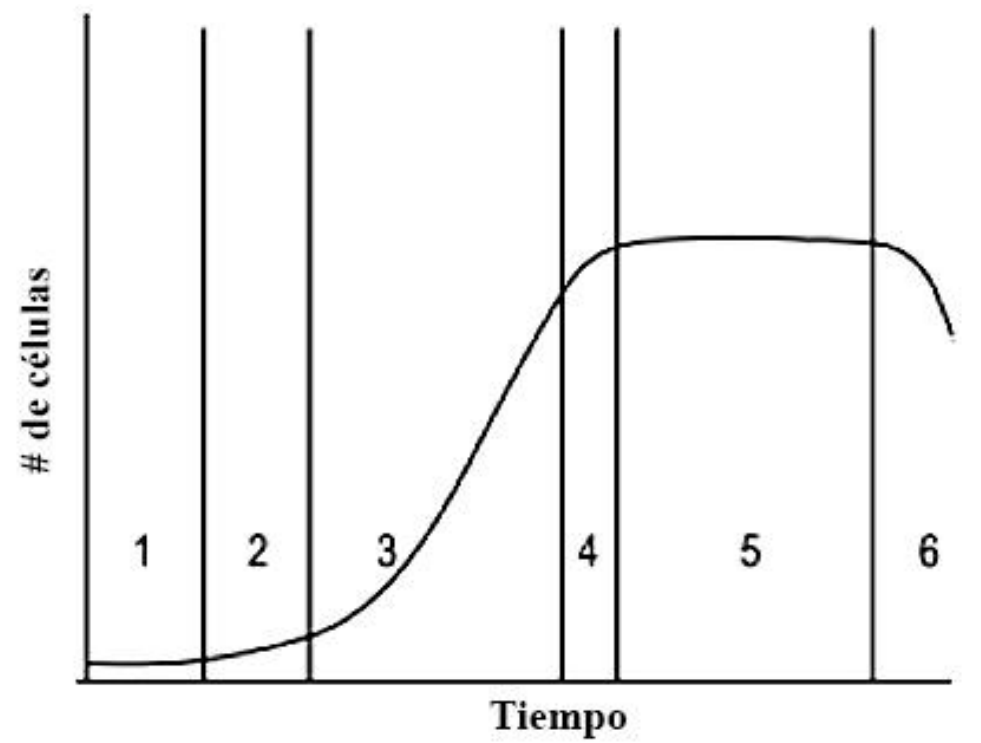

Figura 1. Curva típica de crecimiento microbiano. 1.- Fase lag, 2.- Fase de aceleramiento, 3.- Fase exponencial, 4.- Fase de desaceleración, 5.- Fase estacionaria, 6.- Fase de muerte.

Los microorganismos fijadores de nitrógeno de vida libre abarcan una gama morfológica que va desde los organismos unicelulares como las bacterias y algunas cianobacterias, hasta multicelulares, filamentosas ${ }^{7}$ como Fischerella $T B 22$, que presentan ramificaciones, son capaces de generar fotosíntesis oxigénica, sintetizar clorofila a, poseen al menos una ficobiliproteína, sintetizan glucógeno como producto de almacenamiento, presentan paredes celulares provistas de azúcares, aminos y aminoácidos ${ }^{8}$. Son organismos fijadores de nitrógeno donde la enzima que utilizan es la nitrogenasa ${ }^{9}$. Las cianobacterias fijadoras de nitrógeno 
Crecimiento y metabolismo de Fischerella TB22 en medio de cultivo BG11 ${ }^{0}$. - Martínez-Rosales, A.

contribuyen en gran medida a la presencia de nitrógeno en hábitats terrestres y acuáticos ${ }^{10}$. Fischerella TB22 en particular, que tienen a la nitrogenasa confinada en los heterocitos, los cuales son células especializadas, distribuidas a lo largo o al final del filamento. Los heterocitos están rodeados de una pared glucolipídica gruesa que reduce la difusión del oxígeno hacia las células, cualquier oxígeno que se difunda hacia los heterocistos es reducido rápidamente por hidrógeno; así, la fijación de nitrógeno está espacial y metabólicamente separada del proceso fotosintético. Los heterocistos tienen conexiones intercelulares con las células vegetativas adyacentes, de tal manera que existe un continuo movimiento de los productos de la fijación de nitrógeno desde los heterocistos hacia las células vegetativas y de los productos fotosintéticos desde las células vegetativas hacia los heterocistos ${ }^{11}$. El modelo ${ }^{12}$ de un heterocisto de Fischerella $s p$. con uniones a una célula vegetativa a cada lado (figura 2), enfatiza la situación para N. El heterocisto se caracteriza por una envoltura que comprende una capa de glicolípidos, que forma la barrera principal para la difusión del gas (flechas delgadas) y una capa de polisacárido. La envoltura rodea una pared celular con una membrana externa, una capa de peptidoglicano y una membrana plasmática. Si el aire ingresa o no a los heterocistos a través de las células vegetativas puede regularse mediante un mecanismo de apertura / cierre (representado conceptualmente por flechas naranjas). $\mathrm{El} \mathrm{O}_{2}$ se respira, produciendo ATP. El $\mathrm{N}_{2}$ y $\mathrm{O}_{2}$ compiten por los electrones que se importan como sacarosa de las células vegetativas. Los poros en los extremos de los heterocistos a veces pueden contener cianofina (polímero de poliaspartatomultiarginina). Las enzimas inmiscuidas en el proceso de fijación de $\mathrm{N}$ son las Nase: nitrogenasa y CytOx: citocromo oxidasa; además de $[\mathrm{H}]$ : equivalentes reductores (NAD (P) $\mathrm{H}, \mathrm{FdH})$ derivados del metabolismo de la sacarosa. ${ }^{13}$ afirma que Fischerella sp. mostró capacidad para crecer en un medio de cultivo selectivo (sin nitrógeno), y así comprobar que el amonio medido en el medio es por fijación de $\mathrm{N}_{2}$.

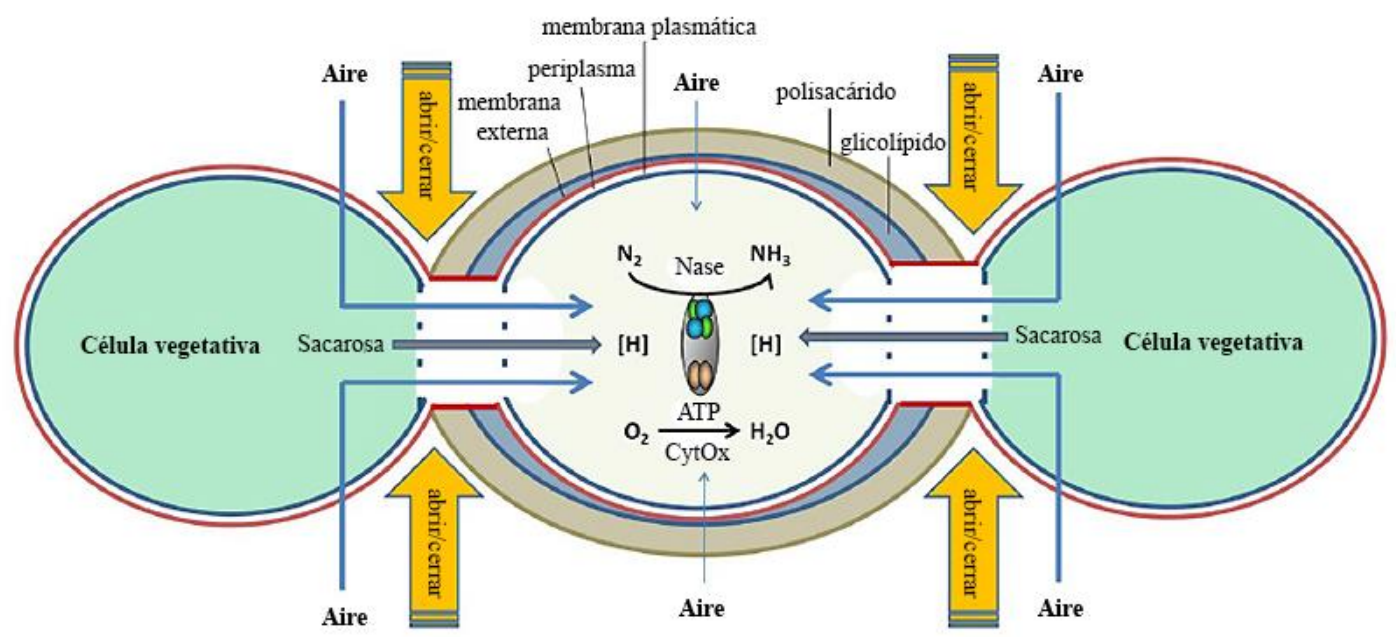

Figura 2. Modelo de un heterocisto con uniones a una célula vegetativa a cada lado ${ }^{12}$.

\section{METODOLOGÍA}

Se prepararon 4 fotobioreactores de columna burbujeada $^{14}$ con $500 \mathrm{ml}$ de medio de cultivo ${ }^{15}$ BG $11^{0}$ con inoculo de Fischerella TB22 (figura
3) al $1 \%(\mathrm{p} / \mathrm{v})$, se pusieron en aireación constante con 12 horas luz y 12 horas obscuridad durante 40 días $^{16}$ a $35^{\circ} \mathrm{C}$, el inoculo fue obtenido de la cepa del Laboratorio de Biotecnología de la Universidad del Mar en fase estacionaria ${ }^{17}$. Los 
Crecimiento y metabolismo de Fischerella TB22 en medio de cultivo BG11 ${ }^{0}$. - Martínez-Rosales, A.

tratamientos por triplicado fueron $\mathrm{T} 1$ donde se ajustó el $\mathrm{pH}$ del medio al $\mathrm{pH}$ inicial, T2 donde se ajustó el volumen (vol) del medio de cultivo, T3 donde se ajustó pH y vol y T4 donde habrá ningún ajuste. Se tomaron 5 muestras de cada tratamiento para su análisis el día $0,3,6,9,12$.

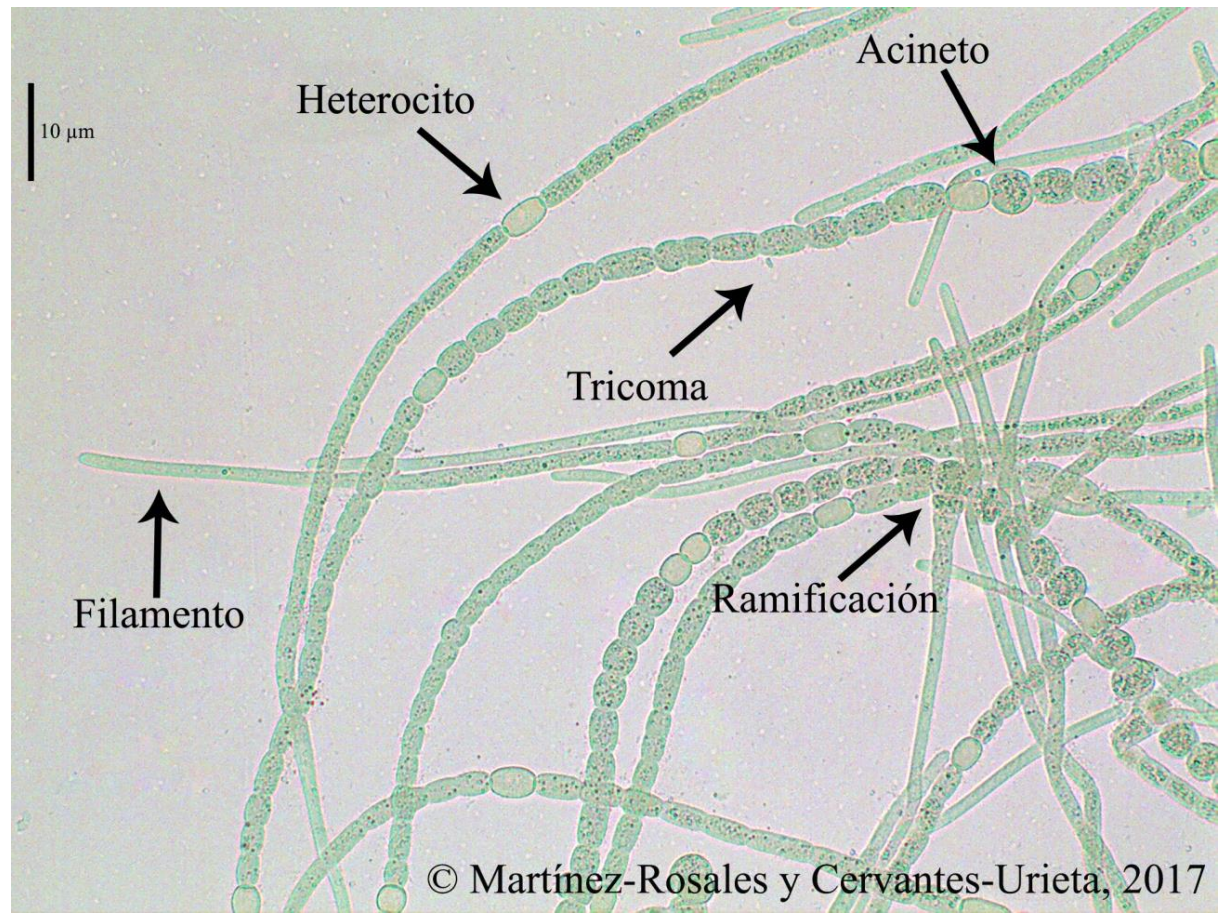

Figura 3. Identificación de células especializadas de Fischerella TB22 con fotografía en microscopio a 40X.

\section{Variables a evaluar}

Para la biomasa por peso seco (BPS) se utilizaron filtros cualitativos de $40 \mathrm{~mm}$ de diámetro y con una abertura de poro de 5-8 $\mu \mathrm{m}$, se enjuagaron con agua acidificada a $\mathrm{pH} 4^{18}$, y se colocaron en una estufa a $70^{\circ} \mathrm{C}$ por 24 horas y se colocaron en un desecador durante 24 horas más para obtener peso constante. Se tomaron una alícuota de $1 \mathrm{~mL}$ de cada tratamiento por triplicado las cuales se filtraron con la ayuda de una bomba de vacío, posteriormente los filtros se colocaron en la estufa a una temperatura de $70^{\circ} \mathrm{C}$ durante 24 horas. Se tomó el peso final del papel $\mathrm{y}$ el peso seco de biomasa se obtuvo por diferencia de peso $^{19}$. Para la densidad óptica (DO) se sonicaron las muestras durante 5 minutos a una frecuencia de $42 \pm 6 \mathrm{khz}$. Se tomó una alícuota de $1 \mathrm{ml}$ de muestra de cada tratamiento por triplicado, se adicionó $1 \mathrm{ml}$ de BG1 $11^{0}$, se midieron en un espectrofotómetro $\mathrm{UV} / \mathrm{V}$ is a $550 \mathrm{~nm}$. Para la medición de amonio en el medio de cultivo $\left(\mathrm{NH}_{4}^{+}\right)$se usó la técnica del manual ${ }^{20}$. Se tomó una alícuota de $5 \mathrm{ml}$ de muestra de cada tratamiento por triplicado y se pusieron a centrifugar en tubos Falcon a 3500 rpm por $10 \mathrm{~min}$, se retiró el sobrenadante a otro tubo y se agregó: 1 gota $(0.05 \mathrm{ml}-50 \mu \mathrm{L})$ de $\mathrm{MnSO}_{4} 0.003 \mathrm{M}$., $0.5 \mathrm{~mL}$ de $\mathrm{NaClO}$ y $0.6 \mathrm{~mL}$ de Fenato inmediatamente después de la solución de $\mathrm{NaClO}$. Se agitó vigorosamente tras cada adicción. Se dejaron reposar $10 \mathrm{~min}$ y se midieron a una absorbancia de $630 \mathrm{~nm}$ en un espectrofotómetro UV/Vis. La lectura del pH se tomó con un potenciómetro marca Hanna modelo HI5221 directamente en el medio de cultivo de cada tratamiento.

\section{Análisis estadístico}

Se utilizó un diseño completamente al azar con análisis de medidas repetidas. Los datos se analizaron con el paquete estadístico Statistica versión 7.0. 
Crecimiento y metabolismo de Fischerella TB22 en medio de cultivo BG11 ${ }^{0}$. - Martínez-Rosales, A.

\section{RESULTADOS Y DISCUSIÓN}

No hubo diferencia en las variables evaluadas entre tratamientos, pero si entre días. El mayor crecimiento en biomasa ocurrió en el día 9 y 12 (figura 4a) no existiendo diferencias significativas entre ellos: se obtuvieron en promedio $6.8 \pm 0.12 \mathrm{mg}$ de $\mathrm{NH}_{4}{ }^{+}$y $7 \pm 0.18 \mathrm{mg}$ el día 12. ${ }^{21}$ reportaron en un experimento similar con Fischerella sp. en condiciones de aireación la producción de amonio de $0.44 \pm 0.13 \mathrm{mg} \mathrm{L}^{-1}$ a los 5 días, en este trabajo la producción de amonio de Ficherella TB22 (figura 4b) a los 5 días fue superior $\left(20 \mathrm{mg} \mathrm{L}^{-1}\right)$, esto puede ser atribuido a que estudiaron una especie diferente a la este trabajo, reportaron también con Fischerella sp. $8.34 \pm 0.72 \mathrm{mg} \mathrm{L}^{-1}$ de clorofila, en este trabajo Fischerella TB22 reportó en el T4 $8.03 \pm 0.2 \mathrm{mg} \mathrm{L}^{-1}$ (figura $4 \mathrm{c}$ ), siendo T4 el mejor tratamiento en esta variable. El ajuste de $\mathrm{pH}$ y vol en el T3 (figura 4d) mostró mejor producción de amonio en el día 9. Los resultados de biomasa (figura 4a) y pH (figura 4d) confirman lo dicho por $^{22}$ que las cianobacterias son capaces de mantener un crecimiento sostenido entre un $\mathrm{pH}$ de 6,0 y 10,0 con un óptimo a $\mathrm{pH} 8,0$. Se coincide $\operatorname{con}^{23}$ en que la variación del $\mathrm{pH}$ está directamente relacionada con el incremento celular debido al aumento en el consumo de $\mathrm{CO}_{2}$, trayendo como consecuencia la alcalinización del medio. El pH se incrementó debido al consumo del fosforo por las cianobacterias, esto debido a que el medio de cultivo perdió su capacidad de amortiguamiento como reportan ${ }^{24}$ en su trabajo con microalgas, para evitar pérdidas de biodisponibilidad de $\mathrm{P}$, sin embargo, en este trabajo no afectó en el rango de crecimiento.
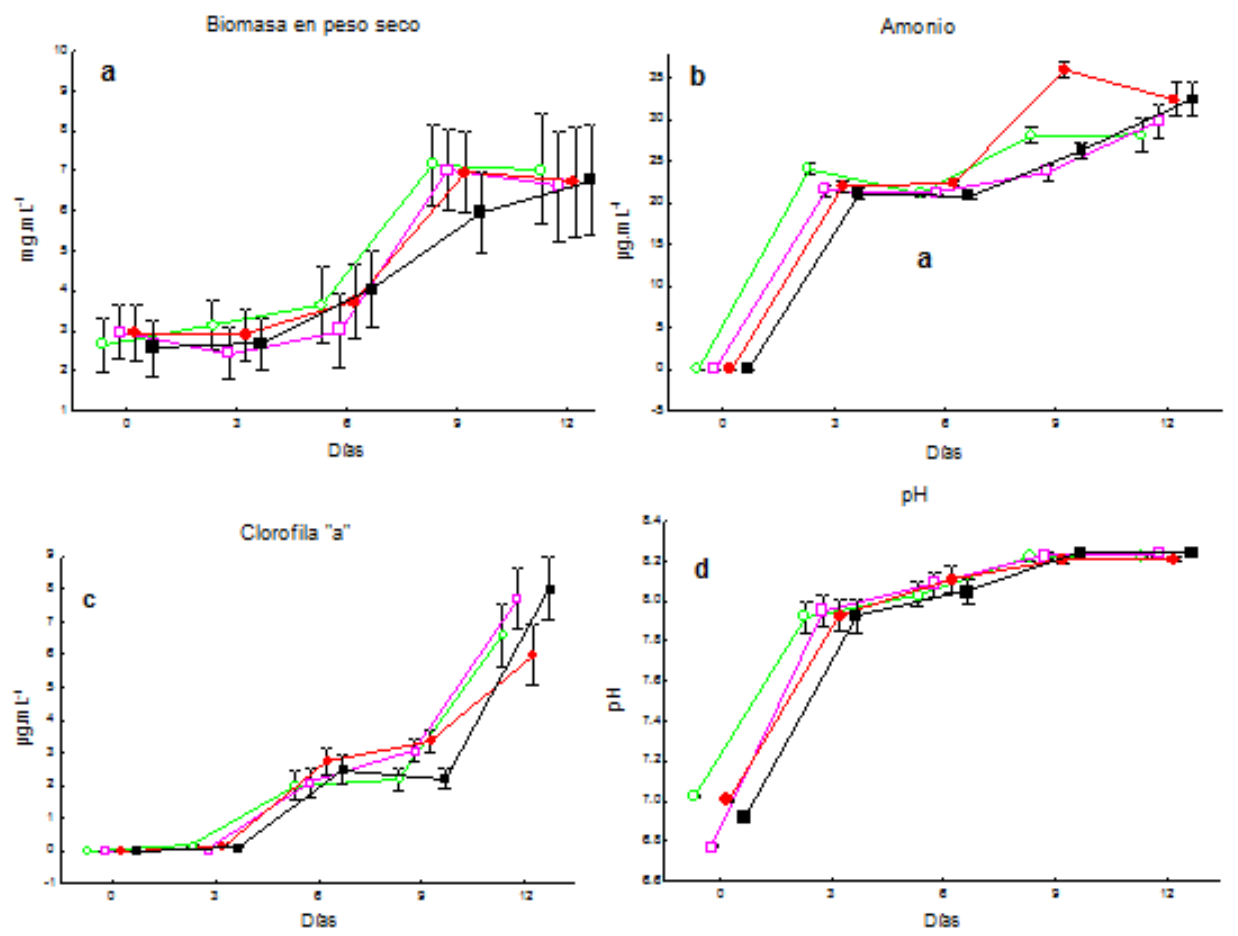

Figura 4. a) Biomasa en peso seco. b) Concentración de amonio. c) Clorofila "a". d) Medición de pH de Fischerella TB22

$\mathrm{T} 1=(\circ)$ Ajuste de $\mathrm{pH}, \mathrm{T} 2=(\square)$ Ajuste de volumen de medio BG11 ${ }^{0}, \mathrm{~T} 3=(\bullet)$ Ajuste de $\mathrm{pH}$ y volumen de medio BG1 $1^{0}$, $\mathrm{T} 4=(\mathbf{\bullet})$ control sin ajustes.

Los resultados de DO (figura 5) demostraron la misma tendencia que la biomasa en peso seco.
La sonicación ayudó a homogenizar el inóculo además de separar las células encadenadas y 
Crecimiento y metabolismo de Fischerella TB22 en medio de cultivo BG110 . - Martínez-Rosales, A.

facilitó las mediciones por espectrofotometría. Se encontró una relación positiva (figura 6) entre la medición de absorbancia y el peso seco según $\left(\mathrm{y}=0.022 \mathrm{e}^{0.048 \mathrm{x}}, \mathrm{R}^{2}=0.948\right)$.

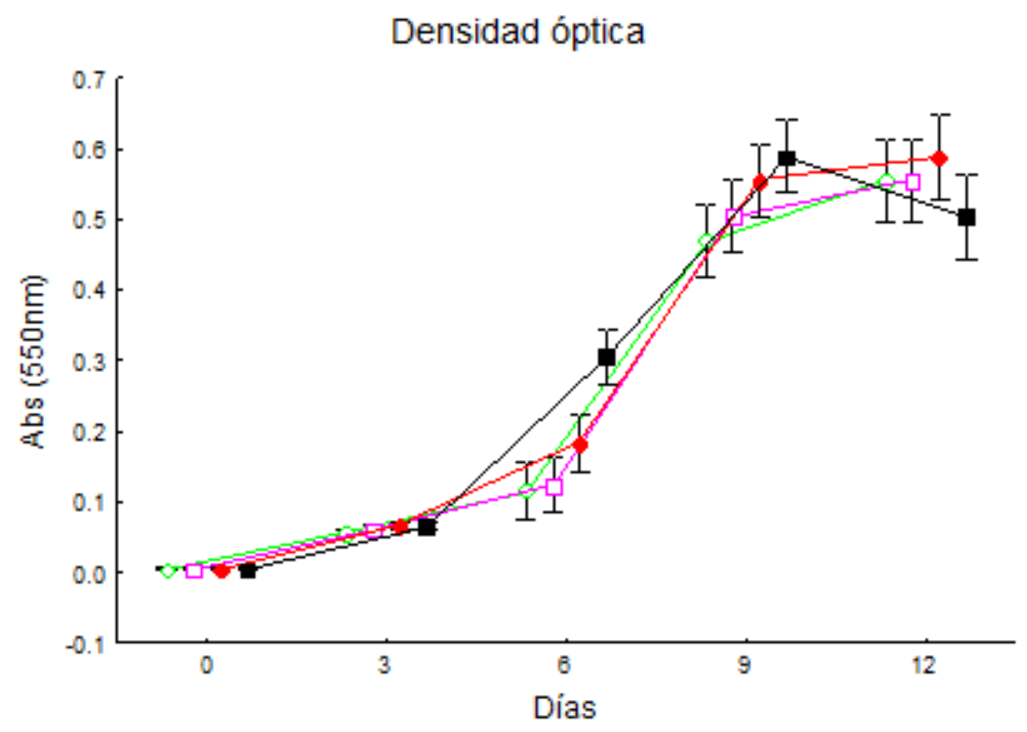

Figura 5. Densidad óptica de Fischerella TB22. $\mathrm{T} 1=(\odot)$ Ajuste de $\mathrm{pH}, \mathrm{T} 2=(\square)$ Ajuste de volumen de medio BG11 ${ }^{0}$, $\mathrm{T} 3=(\bullet)$ Ajuste de $\mathrm{pH}$ y volumen de medio $\mathrm{BG} 11^{0}, \mathrm{~T} 4=(\boldsymbol{\bullet})$ control sin ajustes.

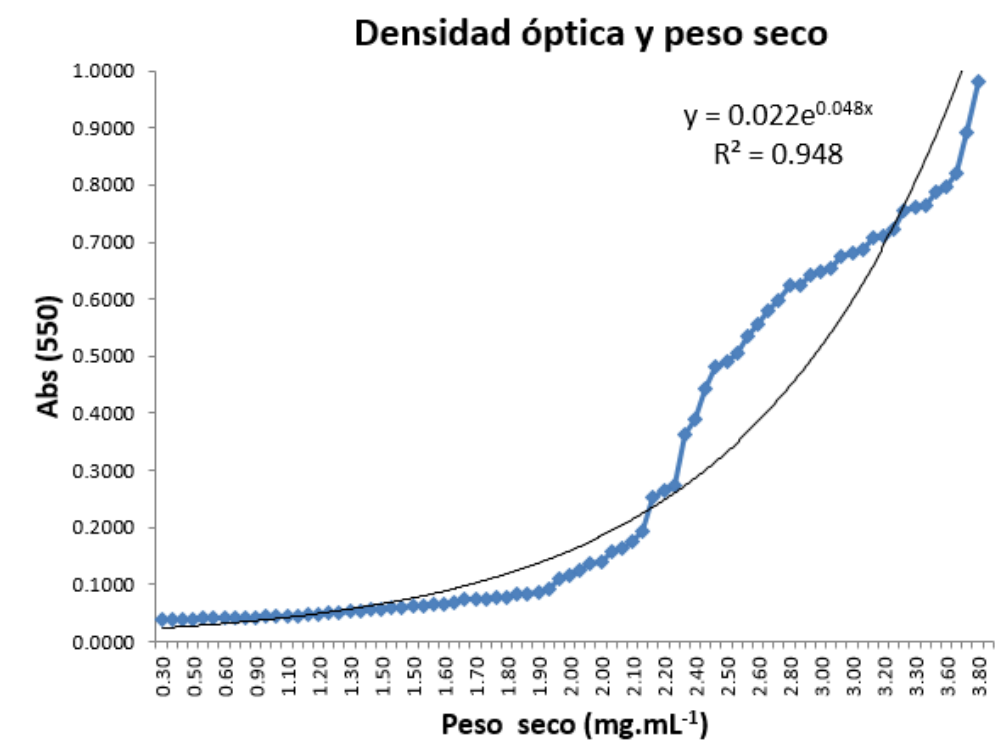

Figura 6. Relación entre la densidad óptica y peso seco de Fischerella TB22.

En el mismo periodo de cinética con consorcios cianobacterianos, ${ }^{16}$ y ${ }^{25}$ obtuvieron resultados similares (Tabla 1), las diferencias en las variables evaluadas se atribuyen a que hubo diferentes géneros en las cepas evaluadas, en este trabajo se utilizó únicamente a Fischerella TB22 aislada. 
Crecimiento y metabolismo de Fischerella TB22 en medio de cultivo BG11 ${ }^{0}$. - Martínez-Rosales, A.

Tabla 1. Comparación de resultados de trabajos con cianobacterias.

\begin{tabular}{lccccc}
\hline & $\mathbf{p H}$ & Biomasa $(\mathbf{m g})$ & $\begin{array}{c}\text { DO } \\
(\mathbf{a b s})\end{array}$ & $\begin{array}{c}\mathbf{C L a} \\
\left(\boldsymbol{\mu g . m L} \mathbf{H}^{-1}\right)\end{array}$ & $\begin{array}{c}\mathbf{N H}_{\mathbf{4}} \\
\left(\boldsymbol{\mu g} . \mathbf{m L}^{-1}\right)\end{array}$ \\
\hline $\mathbf{1 6 *}$ & $6.8 \pm 0.10$ & $8.12 \pm 0.05$ & $0.4 \pm 0.01$ & $10.42 \pm 0.63$ & $34.5 \pm 4.6$ \\
\hline $\mathbf{2 5 *}$ & N/A & $5.8 \pm 0.1$ & N/A & $4.12 \pm 0.95$ & $12.70 \pm 3.8$ \\
\hline Este trabajo & $8.22 \pm 0.01$ & $6.95 \pm 0.61$ & $0.4 \pm 0.09$ & $7.7 \pm 0.94$ & $30.7 \pm 2.08$ \\
\hline
\end{tabular}

*Utilizaron consorcios de cianobacteria

\section{CONCLUSIONES}

Las variables que se midieron de la curva de crecimiento de las cianobacterias, siguieron el patrón de una curva típica de crecimiento microbiano. El noveno día de crecimiento de Fischerella TB22 es el mejor para la aplicación como biofertilizante ya que tiene su máxima producción de amonio. Recuperar el volumen y mantener el $\mathrm{pH}$ como al inicio no fue relevante para su desarrollo. Las cianobacterias mantuvieron su crecimiento en el rango del $\mathrm{pH}$ de 7.3 a 8.6. La sonicación ayudó a homogenizar el inóculo y facilitó las mediciones por espectrofotometría.

\section{REFERENCIAS}

1. Benavente-Valdés, J. R., et al. Tecnología de cultivo de microalgas en fotobiorreactores. Acta Química Mexicana, 2012, vol. 4, no 7, p. 1-12. Disponible en:

https://www.researchgate.net/publication/26256 0081_Tecnologia_de_Cultivo_de_Microalgas en_Fotobiorreactores

2. Lee, E. Phycology (3rd Edition). Estados Unidos: Cambridge University Press. 1999.

3. Campos, Victoriano, et al. Cianobacterias y riesgos potenciales de toxicidad en aguas continentales de Chile. Boletín Micológico, 2005, vol. 20. Disponible en:

https://micologia.uv.cl/index.php/Bolmicol/arti cle/view/279
4. Ho, Ming-Yang, et al. Extensive remodeling of the photosynthetic apparatus alters energy transfer among photosynthetic complexes when cyanobacteria acclimate to far-red light. Biochimica et Biophysica Acta (BBA)Bioenergetics, 2020, vol. 1861, no 4, p. 148064. Disponible en:

https://www.sciencedirect.com/science/article/p ii/S0005272819301033

5. Arredondo Vega, B. O., Voltolina, D. Concentración, recuento celular y tasa de crecimiento. Métodos y herramientas analíticas en la evaluación de la biomasa microalgal, 2007, vol. 1, p. 17-25. Disponible en:

https://www.researchgate.net/profile/Domenico Voltolina/publication/253237563_CONCENT RACION_RECUENTO_CELULAR_Y TASA _DE_CRECIMIENTO/links/00b4953c92711ed 8fb000000.pdf

6. Arredondo Vega, B.O., Cordero Esquivel, B., Herrero, C. y Abalde, J. Manual de Técnicas Bioquímicas Aplicadas en Ficología. Manual de Prácticas del 1er. Curso Teórico Práctico: Aplicaciones Biotecnológicas del Cultivo de Microalgas. La Paz, Baja California Sur, México. Septiembre 1-5, 1997; 40 págs.

7. Mayz-Figueroa, J. Biological Nitrogen Fixation. Revista Científica UDO Agrícola, 2004; 4(1), 1-20. Disponible en: http://www.bioline.org.br/abstract?cg04001 
Crecimiento y metabolismo de Fischerella TB22 en medio de cultivo BG11 ${ }^{0}$. - Martínez-Rosales, A.

8. Carr, N., y Whitton, B. The Biology of Cyanobacteria (2nd Edition). California: University of California at Berkeley Press. 1982.

9. Stainer, R., Ingraham, J., Wheels, M., y Painter, P. Microbiología Segunda Edición. Barcelona: Editorial Reverté. 2005.

10. Freire, Elizabeth; Koch, Alma; Salvador, Lorena. Evaluación del potencial biofertilizante de consorcios de Cianobacterias en pasto Raygrass (lolium multiflorum). ECUADOR ES CALIDAD: Revista Científica Ecuatoriana, 2016, vol. 4, no 1. Disponible en:

https://revistaecuadorescalidad.agrocalidad.gob. ec/revistaecuadorescalidad/index.php/revista/art icle/view/27

11. Todar, K. Textbook of bacteriology. Important groups of prokaryotes. 2015; http://www.textbookofbacteriology.net

12. Stal, Lucas J. The effect of oxygen concentration and temperature on nitrogenase activity in the heterocystous cyanobacterium Fischerella sp. Scientific Reports, 2017, vol. 7, no $1, \quad$ p. 1-10. Disponible en https://www.nature.com/articles/s41598-017$\underline{05715-0}$

13. Martínez A. K. Establecimiento de las condiciones de cultivo de cianobacterias fijadoras de nitrógeno, aisladas de suelos cultivados de papaya. Tesis de Maestría en Ciencias Ambientales. Universidad del Mar, Puerto Ángel, Oaxaca. 2010.

14. Reichert, Carolina da Cruz; Reinehr, Christian Oliveira; Costa, Jorge Alberto Vieira. Semicontinuous cultivation of the cyanobacterium Spirulina platensis in a closed photobioreactor. Brazilian Journal of Chemical Engineering, 2006, vol. 23, no 1, p. 23-28. Disponible en:

https://www.scielo.br/scielo.php?pid=S0104$\underline{66322006000100003 \& \text { script}=\text { sci_arttext }}$
15. Rippka, Rosmarie, et al. Generic assignments, strain histories and properties of pure cultures of cyanobacteria. Microbiology, 1979, vol. 111, no 1, p. 1-61. Disponible en: https://www.microbiologyresearch.org/content/j ournal/micro/10.1099/00221287-111-1-1

16. Ramírez-López C. Efecto de la aireación y la irradiación sobre un consorcio de cianobacterias fijadoras de nitrógeno. Tesis. Universidad del Mar, Campus Puerto Ángel. 2009; 84 pp.

17. Vonshak, A.; Maske, H. Algae: growth techniques and biomass production. En Techniques in bioproductivity and photosynthesis. Pergamon Press, Oxford, 1982. Disponible en:

http://www.bashanfoundation.org/contributions /Vonshak-A/1980.-Vonshak-AL.pdf

18. Vonshak, Avigad. Spirulina: Growth, Physiology and. Spirulina Platensis Arthrospira: Physiology, Cell-Biology And Biotechnology, 1997, p. 43. Disponible en:

https://books.google.com.mx/books?hl=es\&lr= \&id=RUZZDwAAQBAJ\&oi=fnd\&pg=PA43\& dq=Spirulina:+growth, + physiology + and + bioch emistry:+Physiology+cell-

biology+and+Biotechnology.+\&ots=zdOsR -

Xij\&sig=w7dnsDPz0V8kXIu_93hwASMZ3E8 \#v=onepage\&q=Spirulina\%3A\%20growth\%2C $\% 20$ physiology $\% 20$ and $\% 20$ biochemistry $\% 3 \mathrm{~A}$

$\% 20$ Physiology\%20cell-

biology\%20and\%20Biotechnology.\&f=false

19. Arredondo-Vega, B., Cordero-Esquivel, B., Voltolina, D. Determinación de proteínas por métodos espectrofotométricos. Métodos y herramientas analíticas en la evaluación de la biomasa microalgal. Centro de Investigaciones Biológicas del Noroeste. Capítulo 4. 2007; 31$34 \mathrm{pp}$.

20. APHA-AWA-WPCF. Standard methods for the examination of water and wastewater. 18th 
Crecimiento y metabolismo de Fischerella TB22 en medio de cultivo BG11 ${ }^{0}$. - Martínez-Rosales, A.

edition. American Public Health Association. Washington. D. C., U. S. A. 1992.

21. Rajabnasab, Mahboobeh, et al. Adaptation of the Cyanobacterium fischerella sp. ISC 107 to the combined effects of $\mathrm{pH}$ and carbon dioxide concentration. Plant Physiology, 2017, vol. 7, no 4, p. 2163-2171. Disponible en:

http://ijpp.iau-saveh.ac.ir/article_537981.html

22. Morales, Ever, et al. Crecimiento, producción de pigmentos y exopolisacáridos de la cianobacteria Anabaena sp. PCC 7120 en función del pH y CO2. Interciencia, 2002, vol. 27, no 7, p. 373-378. Disponible en:

https://www.redalyc.org/pdf/339/33907007.pdf

23. Brito, D. J., et al. Effect of three sources of nutrients on biomass and pigment production of freshwater microalgae Hyaloraphidium contortum Efecto de tres fuentes de nutrientes en la producción de biomasa y pigmentos de la microalga dulce acuícola Hyaloraphidium contortum. Revista Bio Ciencias, 2016, vol. 4, no 1, p. 15-26. Disponible en:

https://www.researchgate.net/profile/Julio_Coli vet/publication/303401862_Effect_of three_so urces_of_nutrients_on_biomass_and_pigment_ production_of freshwater_microalgae_Hyalora phidium_contortum/links/5740efdb08ae9f741b 34e4bf/Effect-of-three-sources-of-nutrients-onbiomass-and-pigment-production-of-

freshwater-microalgae-Hyaloraphidiumcontortum.pdf

24. Beltrán-Rocha, Julio C., et al. Biotratamiento de efluentes secundarios municipales utilizando microalgas: Efecto del $\mathrm{pH}$, nutrientes ( $\mathrm{C}, \mathrm{N}$ y $\mathrm{P}$ ) y enriquecimiento con $\mathrm{CO}_{2}$. Revista de biología marina y oceanografía, 2017, vol. 52, no 3, p. 417-427. Disponible en: https://scielo.conicyt.cl/scielo.php?pid=S0718$\underline{19572017000300001 \& \text { script }=\text { sci_arttext\&tlng= }}$ p

\section{Alonso-Santos E., Trujillo-Tapia Ma. Y Ramírez-Fuentes E. Crecimiento de}

Fischerella sp. (Stigonematales: Cyanobacteria) en ausencia de nitrógeno y carbonatos. Tendencias de Investigación en Biotecnología y Ciencias Agropecuarias. 2015; Pag. 8-17. ISBN 978-607-9453-08-4. Disponible en:

https://www.researchgate.net/profile/Isaac_Luc as/publication/298215267_Tendencias_de_Inve stigacion_en_Biotecnologia_y_Ciencias_Agrop ecuarias/links/56e7318f08ae4c354b1a7b89/Ten dencias-de-Investigacion-en-Biotecnologia-yCiencias-Agropecuarias.pdf 